\title{
FRACTIONATION OF FATTY ACID ESTERS AND ACYLGLYCERIDES WITH PRESSURIZED $\mathrm{CO}_{2}$
}

\author{
N. COTABARREN ${ }^{\dagger}$, P. HEGEL ${ }^{\dagger}$ and S. PEREDA ${ }^{\dagger+}$ \\ $\dagger$ Planta Piloto de Ingeniería Química - (Universidad Nacional del Sur - CONICET)-Camino La Carrindanga km. \\ 7 - 8000 Bahía Blanca - Argentina. \\ $\$$ Thermodynamics Research Unit, School of Engineering, University of KwaZulu-Natal, Howard College Campus, \\ King George V Avenue, Durban 4041, South Africa \\ spereda@plapiqui.edu.ar
}

\begin{abstract}
C Fatty mono- and di-glycerides are products highly used in the food, cleaning and cosmetic industries because of their emulsifying properties. These products can be obtained through different synthesis routes, namely, glycerolysis of vegetable oils, direct esterification of fatty acids with glycerol or partial transesterification of vegetable oils with alcohols. The last two chemical pathways produce fatty acid esters besides mono/diglycerides, which are difficult to split and purify at industrial scale because of its low vapor pressure, low relative volatility, and high viscosity. In this work, we evaluate the fractionation of fatty acid esters and acylglycerides by supercritical $\mathrm{CO}_{2}$ technology. High pressure experimental extractions were carried out at different operating conditions to validate the technology and a rigorous thermodynamic model was used to evaluate the fractionation process.
\end{abstract}

Keywords - Monoglycerides, diglycerides, fatty acid esters, supercritical, carbon dioxide.

\section{INTRODUCTION}

High pressure processes have been widely studied in the last decades, showing they are an interesting technology to transform the concept of chemical plants and biorefineries, in sustainable, more compact and energy efficient process, with less environmental impacts (Arai et al., 2009; Temelli and Ciftci, 2015).

The non-catalytic supercritical alcohol technology is another interesting example of these processes due to its potential to produced biofuels and chemicals from nonedible vegetable oils (Hawash et al., 2009; Valle et al., 2010), residues of the oleochemical industry (Soto et al., 2013) and biomass (Patil et al., 2011, Hegel et al., 2017). In order to obtain a complete triglycerides conversion to fatty acid esters, different authors agree the supercritical alcohol transesterification should be carried out at temperatures higher than $598 \mathrm{~K}$, pressures in the order of 200 bar, and molar ratios of 40:1 alcohol to oil (Sawangkeaw et al., 2010). At these operating conditions it has been reported fatty acid ester concentrations greater than $96.5 \mathrm{wt} . \%$ in the reaction products, both in batch or continuous tubular reactors, after $30 \mathrm{~min}$. of reaction. The advantages of this technology to process vegetable oils with high contents of free fatty acids and water have been mentioned in several articles (Warabi et al., 2004; Tan and Lee, 2011; Velez et al., 2012). The main drawbacks of the supercritical alcohol transesterification are the need of high excess of alcohol, and also high temperatures to achieve complete conversion of triglycerides to fatty acid esters. However, high temperatures (above $598 \mathrm{~K}$ ) can promote the partial degradation of glycerol and unsaturated fatty acid esters (Vieitez et al., 2010), if the reactive mixture has low molar ratio of alcohol to oil (below 40:1) and it is exposed during high reaction times (more than $30 \mathrm{~min}$.). On the other hand, if the transesterification is carried out under milder operating conditions (553 K and 20:1 alcohol to oil), complete conversion is not achieved and mono/diglycerides (acylglycerides from now on) are also obtained in the reaction products (Valle et al. 2010, Vieitez et al., 2010). Notably, acylglycerides are a valuable by-product with many applications in the food and cosmetic industry due to its emulsifying properties (Branen et al., 2001). Thus, the co-production of these surfactants is interesting for present and future biorefineries.

The conventional route to produce mono/diglycerides is the glycerolysis of fats or fatty acids with excess of glycerol, whose final product, due to chemical equilibrium, is a mixture comprising monoglycerides, diglycerides, triglycerides and glycerol. In order to achieve products with high acylglycerides content $(+90$ wt.\%) also a short path distillation, at high temperatures $(473-523 \mathrm{~K})$ and vacuum $(0.01 \mathrm{mbar})$, can be carried out (Bethge, 2014). However, this technology hardly can avoid thermal degradation, the viscous system does not present favorable mass transfer properties, therefore high recirculation may be needed. Short path distillation cannot achieve concentrations greater than 96 wt.\% in acylglycerides (Peter et al., 1992).

Acylglycerides for special formulations can also be produced by direct esterification of fatty acid and glycerol (Sonntag, 1982) or by enzymatic reactions of free fatty acids and glycerol (Sánchez et al., 2014). Moreover, acylglycerides can be obtained via the catalyst-free partial transesterification of vegetable oils using supercritical alcohols. A previous work (Soto et al., 2014) demonstrates that, in $20 \mathrm{~min}$. of reaction, complete conversion of triglycerides can be achieved at temperatures of $573 \mathrm{~K}$, pressures of $130 \mathrm{bar}$ and low alcohol to oil molar ratio (20:1). Under such conditions, the product exhibits a concentration of $20 \mathrm{wt} . \%$ of mono/ acylglycerides and $80 \mathrm{wt} \%$ of fatty acid esters, since the re- 
action is reversible. Also, other works show that it would be possible to rise the surfactant concentration in the products by adding or recycling glycerol at the reactor inlet (Echeverri et al., 2011; Cotabarren, 2017; Martínez et al., 2017).

The supercritical alcohol technology is interesting for next generation biorefineries, where residual vegetable oils with high free fatty acid and water contents should be processed. Figure 1 shows a simplified scheme of the process. Basically, it comprises five steps: i. feed of vegetable oil and alcohol at 180 bar; ii. heating the feed up to $(523-553) \mathrm{K}$; iii. conversion of the vegetable oil to fatty acid esters and acylglycerides; iv. removal of excess of alcohol for recycle and decanted glycerol; v. fractionation of acylglycerides and biodiesel (square highlighted section in the scheme). As already discussed, the operating conditions of the noncatalytic supercritical alcohol transesterification of vegetable oils are well established in the literature. However, few studies are reported concerning the fractionation stage, which is a key part of this technology.

The reaction products, after the removal of excess alcohol and split of decanted glycerol, are an oily mixtures of fatty acid esters and mono/diglycerides. Compared to the conventional process, fractionating this mixture is less complex, since the relative volatility of fatty esters is much higher than that of triglycerides. Nevertheless, achieving high purity of acyl glycerides is still a complex process. Distillation would require high temperature, promoting thermal degradation and making unfeasible to obtain a purity above $90 \mathrm{wt} \%$ acylglycerides (Sonntag, 1982; Compton et al., 2012; Bethge, 2014).

Based on predictions with the Group Contribution with Association Equation of State (GCA-EOS), Soto et al. 2014 show that the fractionation of monoolein and methyl oleate with $\mathrm{CO}_{2}$ would be a viable separation process at temperatures higher than $308 \mathrm{~K}$ and pressures between 90 bar to 150 bar. In this work, the main aim is to evaluate experimentally the technical feasibility of the fractionation of fatty acid esters and acylglycerides

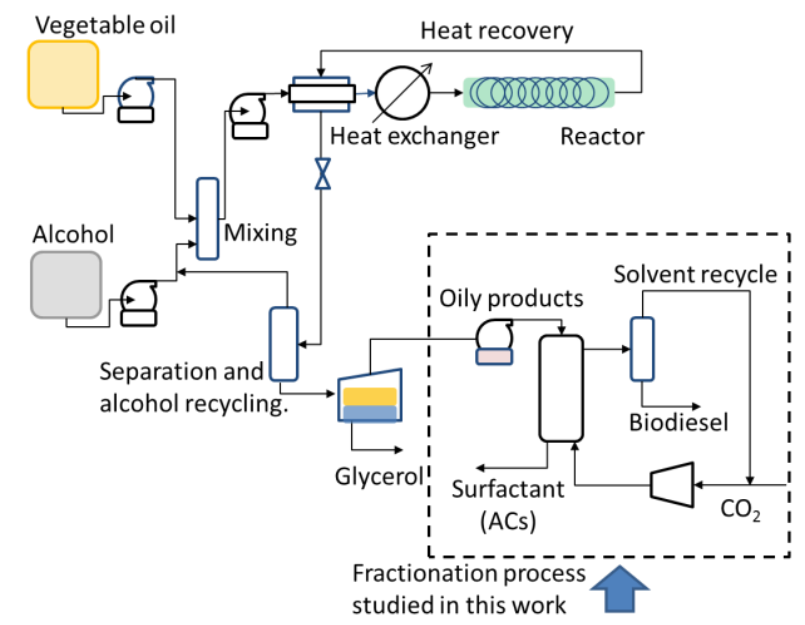

Figure 1. Simplified scheme of the supercritical technology proposed for the production of biodiesel and surfactants. using supercritical $\mathrm{CO}_{2}$. High pressure extractions of oily substrates (20/80 acylglycerides/fatty acid esters) with $\mathrm{CO}_{2}$ are carried out at different operating conditions in order to validate previous modeling studies. Thereafter, an analysis of a continuous extraction column is preformed using the GCA-EOS model.

\section{A. Materials}

\section{METHODS}

The $\mathrm{CO}_{2}$ used in the supercritical extractions was acquired from Air Liquide (99,9 wt.\%, Bahía Blanca, Argentina). High oleic sunflower oil (Dow Agrosciences) was transesterified with supercritical ethanol (99\%, Anedra, Bs.As, Argentina) to produce an oily mixture of fatty acid esters and mono/diglycerides. Pyridine (99.5 wt.\%) used in GC analysis and hexane (96\% wt.\%) used for washing were purchased from Anedra (Bs. As, Argentina) and Cicarelli (Bs. As., Argentina), respectively. Methyl heptadecanoate (99.9 wt.\%), methyl oleate (99.9 wt.\%), monoolein 99.9 (wt.\%), dipalmitin (99.9 wt\%), tetradecane (99.9 wt.\%) from Sigma Aldrich (Bs As., Argentina) were used as analytical GC standards. NMethyl-N-(trimethylsilyl) trifluoroacetamide (MSTFA) acquired from Sigma Aldrich (Bs. As, Argentina) was used as silylating agent.

\section{B. Supercritical production of fatty acid esters and mono/diglycerides}

The mixture of fatty acid esters and mono/digly-cerides was produced by partial transesterification of high oleic sunflower oil with supercritical ethanol in a bench scale high pressure tubular flow reactor. Basically, the equipment consists of two $10 \mathrm{~L}$ tanks for the raw materials $(5 \mathrm{bar} / 323 \mathrm{~K})$, a $2 \mathrm{~L}$ pre-mixer tank (100 bar/473 $\mathrm{K})$, two high-pressure dosing plunger pumps (Dosivac, model DE10/70D and model DEC10/70D, up to 200 bar/0.4 to $2.2 \mathrm{~L} / \mathrm{hr}$.), an electrical pre-heating system $(573 \mathrm{~K}, 0.02 \mathrm{~L}, 350 \mathrm{bar})$ and a stainless steel $316 \mathrm{SS}$ tubular reactor $(0.4 \mathrm{~L}, 200 \mathrm{bar} / 623 \mathrm{~K})$ built in our workshop. The latter is placed in a high temperature muffle with temperature control (Indef-T300, $1000 \mathrm{~K}$ ). In addition, two Pt-100 platinum resistance thermometers are placed at the inlet and outlet of reactor $( \pm 1 \mathrm{~K})$ together with a pressure gauge for high temperatures (Dynisco PG4 series). Downstream of the reactor, a high-pressure tubular heat exchanger (HE) cools down the product mixture with cold water circulation. Finally, a back pressure regulator unit (250 bar) allows to set the operating pressure. Further design specifications and the experimental procedure has been reported in a previous study (Velez et al., 2012). Briefly, in this work, a mixture of high oleic sunflower oil (39 wt.\%) and ethanol (61 wt.\%) was processed at $573 \mathrm{~K}$ and 180 bar at a total mass flow rate of $8 \mathrm{~g} / \mathrm{min}$., i.e a $20 \mathrm{~min}$. residence time. Under such conditions, the oily fraction was a mixture with 19 wt.\% monoglycerides, 5 wt.\% diglycerides and 76 wt.\% fatty acid esters. According to GC analyses, the fatty acid lipid profile of this substrate was $87 \mathrm{wt} \%$ oleic acid, $11 \mathrm{wt} . \%$ palmitic acid, and $2 \mathrm{wt} . \%$ linoleic acid. 


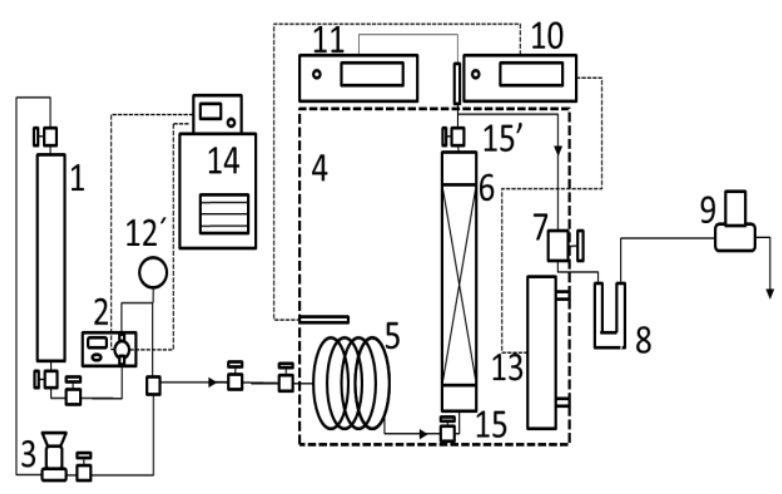

Figure 2. High pressure extractor: 1. Gas stainless steel sample cylinder, 2. HPLC pump, 3. BPR valve, 4. Air thermostatic bath, 5. Heating coil element, 6. Extraction vessel, 7. Needle valve, 8. Refrigerated separator, 9. Flow-meter, 10. Temperature controller, 11. Extractor temperature indicator, 12. Pressure sensors 13. Heating element, 14. Low refrigerated circulator, 15-15'. ON-OFF valves of extractor vessel.

\section{Supercritical $\mathrm{CO}_{2}$ extractor}

Supercritical $\mathrm{CO}_{2}$ fractionations were carried out in a high pressure semi-continuous extractor (see Figure 2). The equipment is described in detail elsewhere (Gañán and Brignole, 2013; Palla et al., 2014).

However, in this work, some modifications were carried out to perform the experiments. The main unit is a high-pressure extraction column $(50 \mathrm{~mL}$ capacity, 1.8 $\mathrm{mL}$ internal diameter) loaded with glass spheres $(1 \mathrm{~mm}$ diameter) that is placed in a convection oven equipped with a PID controller (Novus 380D). The maximum operating temperature and pressure are $353 \mathrm{~K}$ and 300 bar, respectively. In addition, the extraction vessel has a temperature sensor located at the outlet (Thermistorthermometer de Cole-Parmer, $\pm 0.1 \mathrm{~K}$ ), and a calibrated pressure transmitter (Winters LE39000, \pm 0.25 bar) to register the operating conditions. It is worth mentioning that the pressure and temperature instruments are periodically calibrated with a deadweight tester (Fluke, model 3224) and a dry block temperature calibrator (Isotech, Fast-cal series), respectively. Moreover, in the convection oven, a pre-heating coil placed at the extractor inlet stabilizes the solvent temperature during the operation. An HPLC pump (Cole Parmer E74960-05) with external cooling pumps the solvent at constant flow rate and the pressure in the system is controlled by a heated metering valve, specially adapted to avoid $\mathrm{CO}_{2}$ clogging due to the solvent expansion. Finally, the $\mathrm{CO}_{2}$ flow is registered by a mass flow meter (Brooks 4860) placed after a refrigerated U-shaped glass tube used for substrate sample collection. This samples are quantified gravimetrically in a precision balance (Sartorius Entris $224 \mathrm{i}-1 \mathrm{~S}, 0.1 \mathrm{mg}$ ). On the other hand, the total amount of solvent used along the extraction is integrated from the instantaneous flow recorded.

In the experiments, before assembling the column in the oven, about $1 \mathrm{~g}$ of oily substrate was carefully loaded. Then, the entire system was purged with the solvent at ambient conditions, the operating temperature was set at $316 \mathrm{~K}$ and the extraction column was pressurized up to desired values (90 bar, 110 bar, and 150 bar). The system was allowed to reach equilibrium for a period of $60 \mathrm{~min}$. Thereafter, the supercritical fractionation was performed with a constant solvent flow of $0.15 \mathrm{~g} / \mathrm{min}$ (+-0.01 g/min). A low $\mathrm{CO}_{2}$ flow was set to guarantee equilibrium of the solvent phase at the extractor outlet. Once the experience has finished, the raffinate product was recovered by washing the high-pressure column with hexane, which was later removed in a rotoevaporator operated at $323 \mathrm{~K}$ with a vacuum pump and under a slight nitrogen stream. Samples in the U-shaped glass collector were washed with pyridine and diluted up to mark with the solvent in volumetric flasks, likewise the raffinate products. Later, both fractions were analyzed by gas chromatography.

In order to evaluate the operating conditions proposed in previous works (Soto et al., 2014, Cotabarren et al., 2015), the supercritical extractions were carried out at $316 \mathrm{~K}$ and three different levels of pressure (90, 110 and 150 bar) for two fixed solvent to initial substrate ratios, i.e. 30 and $60 \mathrm{CO}_{2}$ /oily substrate fed to the column. According to replicated experiments, uncertainties in the extracted mass were between 1 and $5 \%$.

\section{Gas Chromatograph analyses}

Extract and raffinate samples were analyzed with a gas chromatograph GC-Varian Star 3400 CX equipped with flame ionization detector (FID) and capillary column (J\&W Scientific, model DB-5ht, $15 \mathrm{~m}$ length, $0.32 \mathrm{~mm}$ inner diameter, and $0.10 \mu \mathrm{m}$ film thickness). Moreover, the detector and injector temperature were programmed at $375^{\circ} \mathrm{C}$ and $320^{\circ} \mathrm{C}$, respectively, and the carrier flow rate was set at $2 \mathrm{~mL} / \mathrm{min}$ with a split ratio of $20: 1$. On the other hand, methyl heptadecane, monoolein and dipalmitin were used as references to prepare the calibration curves. Each analysis was performed in triplicate with $50 \mathrm{mg}$ of the oily sample diluted in $5 \mathrm{ml}$ of pyridine. The mixture injected to the GC $(2 \mu \mathrm{L})$ was settled during $30 \mathrm{~min}$. and comprised $0.2 \mathrm{~mL}$ of sample solution, $0.2 \mathrm{~mL}$ of pyridine and $0.1 \mathrm{~mL}$ of silylating agent (MSTFA).

\section{E. Modeling of a counter-current supercritical $\mathrm{CO}_{2}$ extraction column}

The group contribution with association equation of state (GCA-EoS) was used to model the equilibrium phase behavior in this work. Details about the model and the required parameters for the system under study here are given elsewhere (Cotabarren et al., 2014; Soto et al., 2014). On the other hand, high-pressure multistage counter-current columns were simulated using the algorithms developed by Kehat and Ghitis (1981), in order to assess the fractionation of fatty acid esters and acylglycerides. Based on the experimental results, a convenient operating window was studied with the simulator. Specifically, the fractionation of an oily mixture with $20 \mathrm{wt} . \%$ monoolein and $80 \mathrm{wt} . \%$ methyl oleate was assessed with the aim to produce monoglycerides with a purity higher than $99.8 \mathrm{wt} \%$. 


\section{RESULTS AND DISCUSSION}

\section{A. Supercritical $\mathrm{CO}_{2}$ extraction}

Figure 3 shows the yields attained in the supercritical extractions in terms of the mass extracted with respect to the initial mass loaded to the column. The yield at 90 bar is poor, and even after $60 \mathrm{~g} \mathrm{CO}_{2} / \mathrm{g}$ oily substrate, an extraction yield lower than $10 \%$ is obtained along the process. The fatty acid esters solubility in $\mathrm{CO}_{2}$ is very low at this pressure and temperature (Bharath et al., 1989; Espinosa et al., 2002), and as a consequence there is a low extraction yield. An increment of only 20 bar increases notably the extraction yield to about $70 \%$, seven times more extract than at 90 bar. An increase of pressure to 150 bar rises the solvent power; Soto et al. (2014) show that the fatty acid esters are completely soluble in $\mathrm{CO}_{2}$ at 150 bar and $313 \mathrm{~K}$. As Fig. 3 shows, $74 \%$ of the initial mass loaded is extracted at the highest pressure using only $30 \mathrm{~g} \mathrm{CO}_{2} / \mathrm{g}$ oily substrate.

Similar effects of the operating pressure on the extraction yield has been reported in the extraction and fractionation of essential oils (Gañan and Brignole 2013), fixed vegetable oils (Palla et al., 2014; De Melo et al., 2014) and medicinal extracts (Rovetto and Aieta, 2017). At constant temperature, the solvent power increases with the solvent density (Brunner, 2015). In this work, the $\mathrm{CO}_{2}$ density is $0.38,0.64$ and $0.76 \mathrm{~g} / \mathrm{cm}^{3}$ at 90, 110 and 150 bar, respectively.

As can be seen in Fig. 4, which reports the composition of the extracted product, the concentration of fatty acid esters decreases with pressure. The rise of acylglycerides content is more remarkable at 150 bar, depicting an extract that has almost $10 \mathrm{wt} . \%$ of acylglycerides for $30 \mathrm{~g} \mathrm{CO}_{2} / \mathrm{g}$ oily substrate. Also, the results reported in Fig. 4 indicate that the amount of solvent barely affects the composition of the extracted products, except at $150 \mathrm{bars}$, where the use of $60 \mathrm{~g} \mathrm{CO}_{2} / \mathrm{g}$ oily substrate would completely remove the mixture from the column and, of course, the extract composition equals that of the fed mixture, i.e. about $80 \%$.

A pressure increase has a positive effect on the solubility; however, it is detrimental for the selectivity. Higher pressures show a considerable entrainment of acylglycerides due to its molecular affinity with the dissolved fatty esters. As consequence, the selectivity of the process is poor at 150 bar.

Figure 5 shows the composition of the raffinate at different operating conditions. As can be observed, the raffinate does not enrich at 90 bar. In contrast, at 110 bar the enrichment is high, considering that the equipment holds a single equilibrium stage. For instance, at this pressure and using $60 \mathrm{~g} \mathrm{CO}_{2} / \mathrm{g}$ oily substrate, a raffinate with 73 wt.\% acylglycerides was attained. It is worth noting that a further increase of pressure improves the raffinate concentration at low solvent flow ( $30 \mathrm{~g} \mathrm{CO}_{2}$ / g oily substrate). However, the loss of acylglycerides shown before indicates that a reflux would be needed to avoid a low recovery of the more valuable product in a continuous operation. In this regard, Fig. 6 illustrates the recovery of acylglycerides in each experiment.

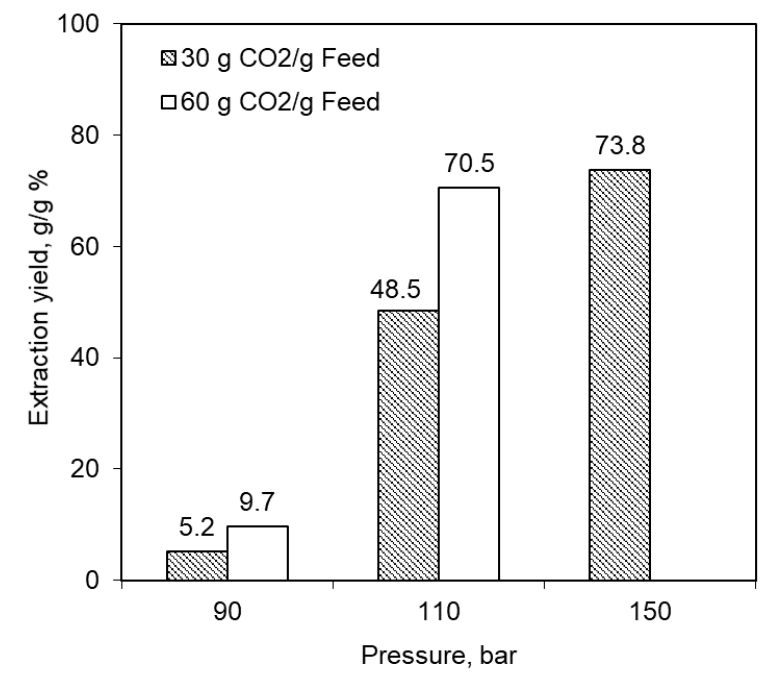

Figure 3. Extraction yields obtained in the supercritical fractionation of fatty acid esters and acylglycerides.

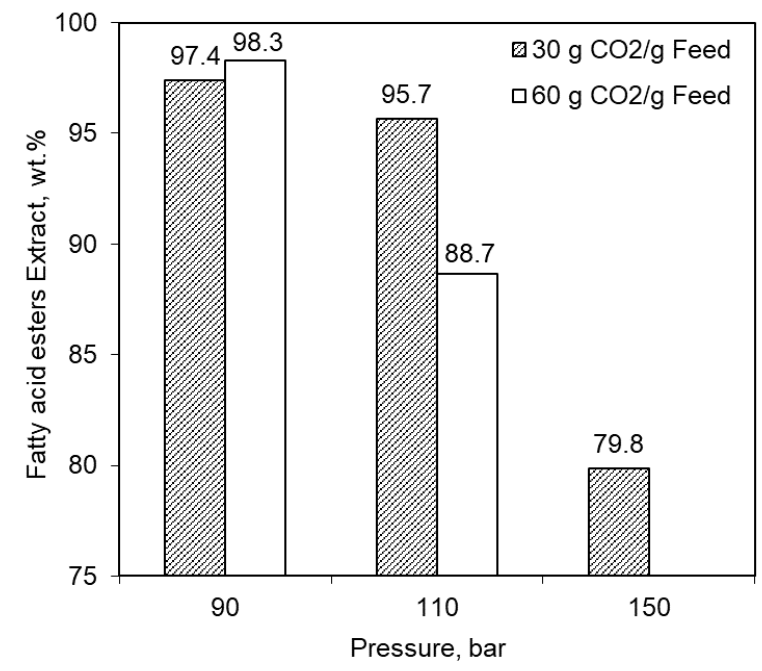

Figure 4. Extract concentration in the supercritical fractionation of fatty acid esters and acylglycerides.

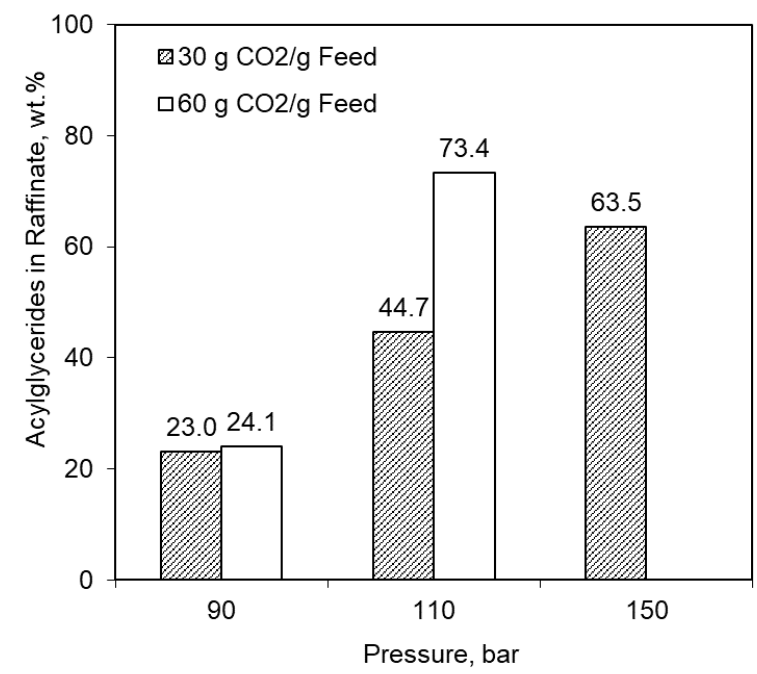

Figure 5. Raffinate concentration in the supercritical fractionation of fatty acid esters and acylglycerides. 


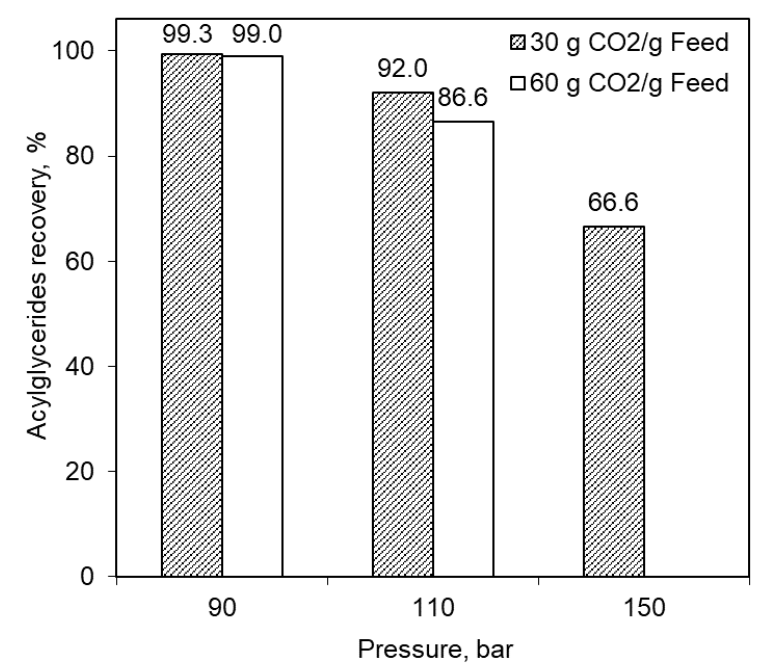

Figure 6. Recovery of acylglycerides in the supercritical fractionation column.

Cotabarren (2017) modeled the experimental data reported in this work with the GCA-EoS. The extension of GCA to the family of fatty acid esters is very robust, since it has been carried out on the basis of diverse type of experimental data in the context of different supercritical applications, namely fractionation of fish oils, production of biodiesel and hydrogenolysis of esters to obtain high molecular weight alcohols. The last two applications dealt mainly with methyl esters of fatty acids, while fish oils are composed of ethyl esters of fatty acids, in analogy with the interest in this work. On the other hand, Soto et al. (2014) extended the model to describe specifically ternary mixtures containing $\mathrm{CO} 2$, acylglycerides and fatty acid esters. The experimental data reported here was useful to challenge the predictive capacity of the GCA-EoS. The results reported by Cotabarren (2017) indicates that the GCA-EoS accurately predicts the phase behavior along the extractions; thus, the GCA-EoS is a good tool to assess a purification process in a continuous multi-stage counter-current column.

In summary, at 110 bar and with enough solvent, it is technically feasible to recover $87 \%$ of the fed acylglycerides with a $73 \mathrm{wt} . \%$ purity in a single equilibrium stage, while the extract phase is a +96 wt. $\%$ fatty acid ester. Consequently, this operating pressure is a worthy alternative to carried out the $\mathrm{CO}_{2}$ fractionation. On the other hand, multiple stages and continuous counter current operation allow reducing the solvent to substrate ratio, improving the economy of the fractionation process.

B. Counter-current $\mathrm{CO}_{2}$ extraction column modeling This section discusses the results of simulating the fractionation of an oily mixture with $20 \mathrm{wt} \%$ monoolein and 80 wt. $\%$ methyl oleate in a high- pressure countercurrent column. Besides the purity of the product, +99.8 wt.\% monoglycerides, the operating pressure was also specified at 110 bar because of the favorable experimental results obtained under this condition.
Figure 7 depicts the solvent need and acylglyceride recovery as the number of equilibrium stages increases from 4 to 10 in a column operating at $316 \mathrm{~K}$ and 110 bar. As expected, the recovery of acylglycerides increases with the number of stages; also, less amount of solvent is required to achieve the specified purity of the raffinate. It is evident that increasing the number of stages above 7 does not enhance practically any of these two variables. Gañan and Brignole (2013) also notice a similar behavior in the fractionation of $\mathrm{T}$. minuta oil with supercritical $\mathrm{CO}_{2}$. In their case, increasing the number of theoretical stages beyond five did not improve the performance of the fractionation column.

Figure 8 shows that the operating temperature of the extraction column has a positive effect on the acylglycerides recovery. For instance, the recovery increases from $88.5 \mathrm{wt} . \%$ at $305 \mathrm{~K}$ to nearly $96 \mathrm{wt} \%$ at $325 \mathrm{~K}$. However, increasing the temperature is detrimental for the required solvent to feed ratio. Therefore, there is a trade-off between the acylglycerides recovery and consumption of $\mathrm{CO}_{2}$, GCA-EOS predictions indicate that temperatures between $313 \mathrm{~K}$ and $318 \mathrm{~K}$ would be appropriate to operate the column.

The reported simulations are in good agreement with previous modeling studies by Soto et al. (2014). In this earlier study, simulations with the GCA-EoS indicated that it would be possible to obtain a refined product with 99.8 wt.\% acylglycerides in a seven stages countercurrent extraction column, operated at $313 \mathrm{~K}$ and 110 bar, and using a solvent to feed ratio of $17 \mathrm{~kg} \mathrm{CO}_{2} / \mathrm{kg}$ of oily substrate. A more detailed analysis of temperature effects carried out in this work, shows that the extraction temperature could be barely higher $(316 \mathrm{~K})$ in order to increase the recovery of monoglycerides (ca. 94 wt.\%) with still reasonable solvent to feed mass ratios (ca. $30 \mathrm{~kg} \mathrm{CO} / \mathrm{kg}$ oily substrate).

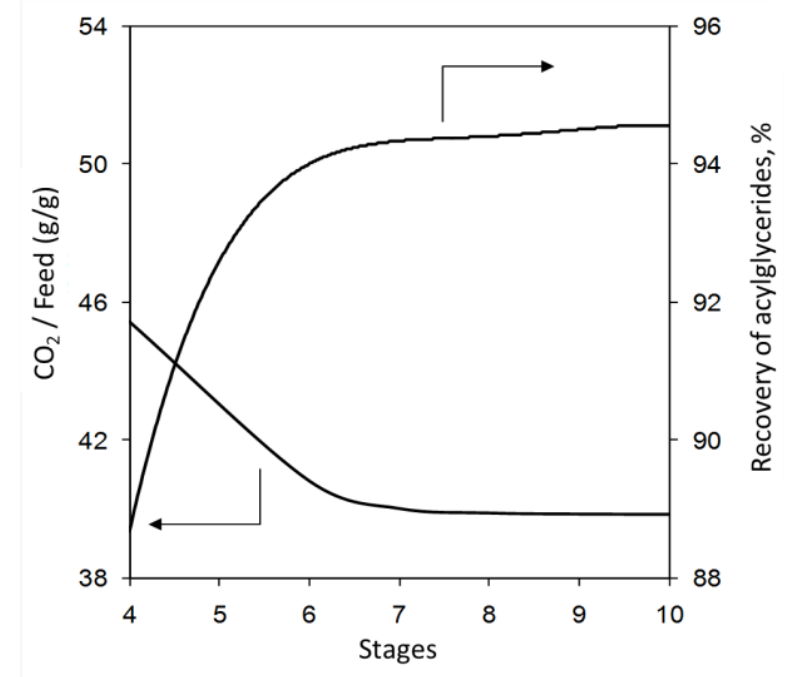

Figure 7. Simulation of a multi-stage counter-current extraction column at $316 \mathrm{~K}$ and 110 bar. GCA-EOS prediction of the effect of theoretical equilibrium stages on the solvent to feed ratio (S/A) and acylglycerides recovery in the raffinate (+99.8 wt.\%). 


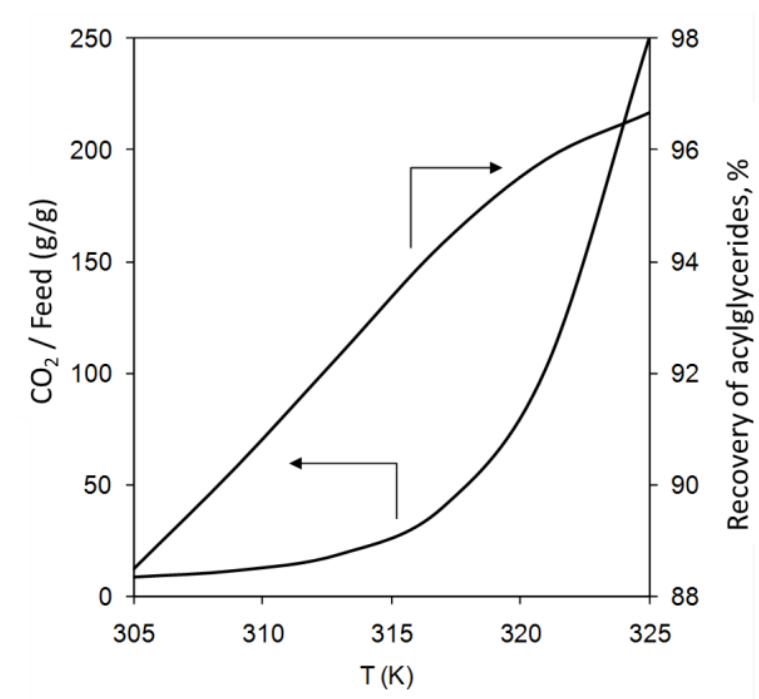

Figure 8. Simulation of a counter-current extraction column of seven theoretical equilibrium stages at 110 bar. GCA-EOS predictions of the effect of temperature on the solvent to feed ratio (S/A) and acylglycerides recovery in the raffinate (+99.8 wt.\%).

\section{CONCLUSIONS}

Experimental fractionation of oily substrates with ca. 20 wt. $\%$ acylglycerides and 80 wt.\% fatty acid esters were carried out in a semi-continuous extraction column at $316 \mathrm{~K}$, pressures between 90 and 150 bar and using two solvent to substrate mass ratios (30 and $60 \mathrm{~g} \mathrm{CO}_{2} / \mathrm{g}$ initial substrate fed to the column). The results confirm previous modeling studies and indicate that the use of supercritical $\mathrm{CO} 2$ to carry out the fractionation of fatty acid esters and monoglycerides is technically feasible. The best extraction results are achieved at 110 bar and $316 \mathrm{~K}$. Under these conditions, in a single semi-batch extraction stage, a raffinate with up to 73 wt.\% acylglycerides is attained using $60 \mathrm{~g} \mathrm{CO}_{2} / \mathrm{g}$ oily substrate.

A continuous counter-current extraction column with supercritical $\mathrm{CO}_{2}$ was modeled at 110 bar to evaluate the effect of other operating variables, such as temperature and number of theoretical equilibrium stages. The simulations show that an extraction column of 7 stages would be appropriate to fractionate oily mixtures with 20 wt.\% monoglycerides. Also, the solvent to feed ratio increases exponentially with temperatures; thus, the extraction column should not operate at temperatures greater than $318 \mathrm{~K}$. A raffinate product with up to 99.8 wt.\% monoglycerides can be obtained in a seven stages extraction column operated at 110 bar and temperatures between $310 \mathrm{~K}$ and $316 \mathrm{~K}$, working with a solvent to feed ratio between 12 and $30 \mathrm{~kg} \mathrm{CO}_{2} / \mathrm{kg}$ of oily substrate, respectively. In that regard, the column performance shows high sensitivity within a narrow operating window.

\section{ACKNOWLEDGMENTS}

The authors acknowledge the financial support granted by the Consejo Nacional de Investigaciones Científicas y Técnicas (PIP 11220150100856 CO), the Ministerio de Ciencia, Tecnología e Innovación Productiva (MinCyT: PICT 2014/2293 and PICT 2016/0907), and Universidad Nacional del Sur (UNS - 24/M133).

\section{REFERENCES}

Arai, K., R.L. Smith Jr. and T.M. Aida, "Decentralized chemical processes with supercritical fluid technology for sustainable society," The Journal of Supercritical Fluids, 47, 628-636 (2009).

Bharath, R., H. Inomata, K. Arai, K. Shoji and Y. Noguchi, "Vapor-liquid equilibria for binary mixtures of carbon dioxide and fatty acid ethyl esters," Fluid Phase Equilibria, 50, 315-327 (1989).

Bethge, D., "Short Path and Molecular Distillation," Vacuum Technology in the Chemical Industry (ed W. Jorisch), Wiley-VCH Verlag GmbH \& Co. KGaA, Weinheim, Germany (2014).

Branen, L.A., P.M. Davidson, S. Salminen and J.H. Thorngate, Food Aditives, Marcel Dekker, Inc. New York (2001).

Brunner, G., "Supercritical process technology related to energy and future directions - An introduction", The Journal of Supercritical Fluids, 96, 11-20 (2015).

Compton, D.L., F.J. Eller, J.A. Laszlo and K.O. Evans, "Purification of 2- Monoacylglycerols Using Liquid CO2 Extraction," J. Am. Oil Chem. Soc., 89, 1529-1536 (2012)

Cotabarren, N., P. Hegel and S. Pereda, "Thermodynamic model for process design, simulation and optimization in the production of biodiesel," Fluid Phase Equilibria, 362, 108-112 (2014).

Cotabarren, N., G. Soto, P. Hegel and S. Pereda, "High pressure processing of vegetable oils and derivatives to obtain value-added products," World congress on oils and fats, Rosario, Argentina (2015).

Cotabarren, N.S., Ingeniería del equilibrio entre fases en biorrefinerías de base oleaginosa, $\mathrm{PhD}$ thesis, Universidad Nacional del Sur (2017).

De Melo, M.M.R., A.J.D. Silvestre and C.M. Silva, "Supercritical fluid extraction of vegetable matrices: Applications, trends and future perspectives of a convincing green technology," The Journal of Supercritical Fluids, 92, 115-176 (2014).

Echeverri, D.A., F. Cardeño and L.A. Rios, "Glycerolysis of soybean oil with crude glycerol containing residual alkaline catalysts from biodiesel production," JAOCS, 88, 551-557 (2011).

Espinosa, S., S. Diaz and E.A. Brignole, "Thermodynamic Modeling and Process Optimization of Supercritical Fluid Fractionation of Fish Oil Fatty Acid Ethyl Esters," Ind. Eng. Chem. Res., 41, 15161527 (2002).

Gañán, N. and E.A. Brignole, "Supercritical carbon dioxide fractionation of $T$. minuta and S. officinalis essential oils: Experiments and process analysis," The Journal of Supercritical Fluids, 78, 12-20 (2013). 
Hawasha, S., N. Kamal, F. Zaher, O. Kenawi and G. El Diwani, "Biodiesel fuel from Jatropha oil via noncatalytic supercritical methanol transesterification," Fuel, 88, 579-582 (2009).

Hegel, P., L. Martín, C. Popovich, C. Damiani, S. Pancaldi, S. Pereda and P. Leonardi, "Biodiesel production from Neochloris oleoabundans by supercritical technology," Chemical Engineering and Processing: Process Intensification, 121, 232-239 (2017).

Kehat, E. and B. Ghitis, "Simulation of an extraction column," Comput. Chem. Eng., 5, 171-180, (1981).

Martínez, A.L., N.S. Cotabarren, P. Hegel and S. Pereda, "Transición de fases en la síntesis de monoglicéridos libre de catalizador," Congreso Argentino de Ingeniería Química, IX CAIQ, Bahía Blanca, Argentina (2017)

Palla, C., P. Hegel, S. Pereda and S. Bottini, "Extraction of jojoba oil with liquid $\mathrm{CO} 2+$ propane solvent mixtures," The Journal of Supercritical Fluids, 91, 37-45 (2014).

Patil, P.D., V.G., Gude, A. Mannarswamy, S. Deng, P. Cooke, S. Munson-McGee, I. Rhodes, P. Lammers and N. Nirmalakhandan, "Optimization of direct conversion of wet algae to biodiesel under supercritical methanol conditions," Bioresource Technology, 102, 118-122 (2011).

Peter, S.K., E.O. Weidner, U.M. Ender and B. A. Czech, Process for the recovery of monoglycerides and diglycerides from a mixtures containing monoglycerides, diglycerides and triglycerides, US Patent 5110509 (1992).

Rovetto, L. and N.V. Aieta, "Supercritical carbon dioxide extraction of cannabinoids from Cannabis sativa L.," The Journal of Supercritical Fluids, 129, 16-27 (2017).

Sánchez, D.A., G.M. Tonetto and M.L. Ferreira, "Enzymatic synthesis of 1,3-dicaproyglycerol by esterification of glycerol with capric acid in an organic solvent system," Journal of Molecular Catalysis B: Enzymatic, 100, 7- 18 (2014).

Sawangkeaw, R., K. Bunyakiat and S. Ngamprasertsith, "A review of laboratory-scale research on lipid conversion to biodiesel with supercritical methanol (2001-2009)," The Journal of Supercritical Fluids, 55, 1-13 (2010).
Sonntag, N., "Glycerolysis of fats and methyl esters Status, Review and Critique," JAOCS, 59, 795A802A (1982).

Soto, G., A. Velez, P. Hegel, G. Mabe and S. Pereda, "Fatty acids recovery from vegetable oil wet sludge by supercritical alcoholysis," Journal of Supercritical Fluids, 79, 62-66 (2013)

Soto, G., P. Hegel and S. Pereda, "Supercritical production and fractionation of fatty acid esters and acylglycerols," The Journal of Supercritical Fluids, 93, 74-81 (2014).

Tan, K.T. and K.T. Lee, "A review on supercritical fluids (SCF) technology in sustainable biodiesel production: Potential and challenges," Renewable and Sustainable Energy Reviews, 15, 2452-2456 (2011).

Temelli, F. and O.N. Ciftci, "Developing an integrated supercritical fluid biorefinery for the processing of grains," The Journal of Supercritical Fluids, 96, 77-85 (2015).

Valle, P., A. Velez, P. Hegel, G. Mabe and E.A. Brignole, "Biodiesel production using supercritical alcohols with a non-edible vegetable oil in a batch reactor," The Journal of Supercritical Fluids, 54, 61-70 (2010).

Velez, A., G. Soto, P. Hegel, G. Mabe and S. Pereda "Continuous production of fatty acid ethyl esters from sunflower oil using supercritical ethanol," Fuel, 97, 703-709 (2012).

Vieitez, I., C. da Silva, I. Alckmin, G.R. Borges, F.C. Corazza, J.V. Oliveira, M. Grompone and I. Jachmanián, "Continuous catalyst-free methanolysis and ethanolysis of soybean oil under supercritical alcohol/water mixtures," Renewable Energy, 35, 1976-1981 (2010).

Warabi, Y., D. Kusdiana and S. Saka, "Reactivity of triglycerides and fatty acids of rapeseed oil in supercritical alcohols," Bioresource Technology, 91, 283-287 (2004).

Received March 2, 2018.

Sent to Guest Editor March 2, 2018.

Accepted December 28, 2018.

Recommended by Guest Editor Patricia M. Hoch 